UDC 536.46:532.517.4

\author{
${ }^{1}$ A.S. Askarova, ${ }^{2}$ R. Leithner, ${ }^{1}$ S.A. Bolegenova*, \\ ${ }^{1}$ V.Ju. Maximov, ${ }^{1}$ A. Aitbayeva \\ ${ }^{1}$ Department of Physics and Technical Physics of al-Farabi Kazakh National University \\ al-Farabi ave.,71, Almaty, Kazakhstan \\ ${ }^{2}$ Institute for Energy and Process Systems Engineering of Carolo Wilhelmina Technical University \\ Franz-Listzstr., 35, Braunschweig, Germany \\ "e-mail: Saltanat.Bolegenova@kaznu.kz
}

\title{
Using CFD code FLOREAN for simulations of industrial boiler
}

\begin{abstract}
Computational fluid dynamics (CFD) becomes more and more reliable tool to analyze the furnace operation under different conditions. This paper provides and overview of the current possibilities of 3D-Finite Volume tool FLOREAN developed at the Institute for Heat and Fuel technology TU Braunschweig. This program is used for simulations of combustion processes in industrial furnaces. FLOREAN has been applied for the calculation of a furnace chamber of Aksu power station fired with low grade coal of Ekibastuz (Kazakhstan). Distributions of different parameters such as temperature, fluid flow properties (velocities, pollutant substances such as $\mathrm{CO}$, NOx) etc. are simulated. These simulations can be used to design furnaces, optimize furnace operation and minimize pollutant emissions.

Keywords: computational fluid dynamics, Multi diameter model,combustion process,Fuel Oil Combustion

Model, Coal Combustion Model.
\end{abstract}

\section{Introduction}

In the last years Computational Fluid Dynamics - has become a more and more reliable tool to check the design of industrial furnaces and power plants [1-3]. The present paper provides an overview of the current capabilities of the CFDcomputer code FLOREAN (acronym for FLOw and REActioN) developed at the Institute for Fuel and Heat Technology, Technical University of Braunschweig, Germany.

Simulation tool FLOREAN allows getting detailed information about furnace performance including velocities, temperature, thermal, radiation and concentration distributions etc. within the furnace and along the walls. The efficient combustion of solid fuel in combustion chambers and the efficient heat transfer to water and steam in steam generators are essential for the economical operation of power plants. This information is useful to evaluate the combustion process and to design optimal furnaces. FLOREAN will also be very useful in improving combustion process of different fuels in industrial boilers, optimizing operation and minimizing pollutant emission.

\section{Mathematical model}

A three-dimensional computational fluid dynamics code was used to analyze the performance of different boilers with pulverized coal combustion at different operation modes. The main objective of this study was to show a number of possibilities of this three-dimensional furnace modeling as an effective method for design, optimization and problem solving in power plant operation.

Consequently, the FLOREAN - code was used to predict thermal and hydrodynamic aspects of flue gases mixing in the near wall region and inside the furnace. In the case of Over Fire Air (OFA) technology the simulations show that effective mixing between flue gases and over fire air is of essential importance for CO reburning and low NOx emissions.

Program FLOREAN is based on the numerical solution of the Reynolds averaged balance equations for mass, species, energy and momentum [14]. It predicts gas flows, species concentrations, temperature fields due to combustion, radiation and convective heat transfer and the pollutant formation and destruction in furnace chambers.

Printed in Kazakhstan 
The transport by diffusion of each value is calculated by an effective exchange coefficient, based on the effective viscosity and the empirical Prandtl-Schmidt number. The mean flow equations are closed by the k- e turbulence model.

The changes of the concentrations of the flue gas components and the fuel due to the combustion are taken into account in the source/sink terms by appropriate sub models. In addition, in the source/sink term the heat balance takes into account the energy release due to the combustion reactions and the significant heat transfer due to radiation using a six flux radiation model by Lockwood etc [5].

The energy balance is written as follows:

$$
\frac{\delta}{\delta x_{i}}\left(\rho U_{i} h\right)=\frac{\delta}{\delta x_{i}}\left\{\frac{\mu_{e f f}}{\operatorname{Pr}}\left(\frac{\delta h}{\delta x_{i}}\right)\right\}+S_{c o m b}+S_{r a d} .
$$

The right hand side of the energy equation contains the source term $\mathrm{S}_{\text {comb }}$ due to the combustion of volatiles, char and formed carbon monoxide. The source/sink term due to radiation is calculated using the six-flux model of Lockwood and Shah [6]. It is mentioned that radiative heat exchange is one of the three basic ways of heat exchange and some researcher successfully couple computer methods and radiative heat exchange phenomena [7]. The time mean temperature is obtained from the calculated enthalpy using polynoms taken out of [8].

In many practical combustion processes, the fuels are liquids or solids, which have to be evaporated, and/or gasified usually prior combustion. The additional consideration of a phase change leads to more complex heterogeneous combustion processes than combustion processes in the gas phase. In FLOREAN, models for combustion of heavy fuel oil and different coal types are included.

Coal Combustion Model. The coal particle size distribution is modeled through different mean diameters. During the combustion, process the coal particle diameters changes. The change depends on the coal type e.g. swelling coal. At the end ash and unburnt carbon is left.

The coal combustion model is divided into five sub models for drying, pyrolysis, combustion of volatiles, carbon monoxide and residual char. The drying model considers the heat necessary for evaporating the moisture content. The pyrolysis model is usually a first order reaction model; more models that are detailed are available. Three different reactions between char and flue gas are considered. The oxidation of the char to carbon monoxide or carbon dioxide and the reduction of carbon dioxide at the surface of the char particle to carbon monoxide. The model incorporates the different effects of oxygen and carbon dioxide diffusion to the particle surface and in the pores and the kinetics of the chemical reaction at the surface as a function of temperature and particle diameter.

The Eddy Dissipation Model according to Magnusson et al is used to predict the combustion of the volatiles and the carbon monoxide formed during char combustion. Gaseous fuels are treated like volatiles [9].

In the case of coal combustion, the two-phase flow can be treated using the Eulerian or the Lagrangian approach to calculate the flow pattern of the solid phase.

Multi diameter model.In the multi diameter model for each particle, class the energy balance of neglectable slip between gas and particles. Therefore, no additional momentum balance is needed. The source/sink term is calculated by:

$$
\begin{aligned}
& \dot{Q}_{P, 1}=\dot{Q}_{C, 1}+\dot{Q}_{R, 1}+\dot{Q}_{C h, 1}-\dot{Q}_{D, 1}-\dot{Q}_{M 1,1}, \\
& \dot{Q}_{C, 1}=\text { heat flux due to convection, } \\
& \dot{Q}_{R, 1}=>\text { heat flux due to radiation, } \\
& \dot{Q}_{C h, 1}=>\text { heat generation due to char combustion, } \\
& \dot{Q}_{D, 1}=>\text { heat loss due to vaporization of water, } \\
& \dot{Q}_{M 1,1}=>\text { heat loss due to mass loss of the par- }
\end{aligned}
$$
ticle, e.g. drying, pyrolysis etc.

The convective heat flux is calculated under the assumption of spherical particles:

$$
\dot{Q}_{C, 1}=n_{P, 1} \cdot \pi \cdot d_{P, j}^{2} \cdot \alpha_{1}\left(T_{G}-T_{P}\right) .
$$

There is $n_{P, 1}$ the number of part icles in the control volume.

$$
n_{P, 1}=\frac{V \cdot \rho_{s} \cdot m_{P, 1}}{\rho_{P, 1} \cdot \frac{\pi}{6} \cdot d_{P, j}^{3}}
$$


$V=>$ volume,

$\rho_{s}=>$ density of suspension,

$\rho_{P, 1}=>$ density of particles,

$m_{P, 1}=>$ mass fraction of the particles.

The heat transfer coefficient $\alpha_{1}$ between particle and gas has been calculated using constant Nusselt Number of magnitude two.

The radiative heat flux to the particles is calculated from the difference of absorbed and emitted radiation:

$$
\dot{Q}_{R, 1}=V \cdot K_{a, P, 1} \cdot\left(\frac{4}{3} \pi \sum B_{i}-4 \sigma T_{P, 1}^{4}\right) .
$$

Here $\mathrm{B}_{\mathrm{i}}$ is the heat flux of the six flux radiation model and $K_{a, P, 1}$ the absorption coefficient of the particles.

The sinktermin the particle energy balance due to mass lossis calculated as follows:

$$
\begin{aligned}
& \dot{Q}_{M 1,1}=c_{P, 1} \cdot T_{P, 1} \cdot\left(\dot{m}_{D, 1}+\dot{m}_{V, 1}+\dot{m}_{C h a i r, C h, 1}\right), \\
& \dot{m}_{D, 1}=>\text { mass loss due to vaporization, } \\
& \dot{m}_{V, 1}=\text { mass loss due to devolatilization, }
\end{aligned}
$$$$
m_{\text {Chair }, C h, 1}=>\text { mass loss due to char burnout. }
$$

Devolatilization, char burnout and changing of particle diameter and density are calculated using models described above In the Arrhenius expressions of the combustion model the particle temperature is used calculated from the energy balance of each particle class. The number of particle classes is arbitrary but increasing number of classes means increasing memory demand and computation time.

Fuel Oil Combustion Model. Three phases of droplet combustion are considered:

Heating phase: heat from the gas phase causes the droplet surface to heat up. Much of the energy is convected into the droplet until the entire droplet is approaching the boiling temperature.

Fuel evaporation stage: Fuel evaporates into the gas phase and a combustible mixture is formed; the droplet diameter decreases in time. The droplet evaporation model includes heat and mass transfer. Usually the continuous gas phase is at a higher temperature than the fuel droplets [10].

Combustion phase: The oil combustion model uses the Eddy Dissipation Model for the combustion of evaporated combustible species in the gas phase.
The changes of the concentrations of the flue gas components and the fuel due to the combustion are taken into account in the source/sink terms.

Chemically Reactive Species (Combustion).Five gaseous Species are considered: oxygen, volatile matter, carbon monoxide and final combustion products consisting of carbon dioxide and water vapour. Three solid species char, coal and ash are taken into consideration. The mass balance of each species $\mathrm{k}$ is as follows:

$$
\frac{\delta}{\delta x_{i}}\left(\rho U_{i} m_{k}\right)=\frac{\delta}{\delta x_{i}}\left\{\frac{\mu_{e f f}}{S c}\left(\frac{\delta m_{k}}{\delta x_{i}}\right)\right\}+S_{k},
$$

with $m_{k}$ being, the mass fraction of species $\mathrm{k}$. Sc is the Schmidt number and $\mathrm{S}_{\mathrm{k}}$ the source/sink term due to the reaction.

NOx formation model. Within the combustion of fossil fuels, nitric oxide is built up through different reaction paths. The main reactions are the oxidation of molecular nitrogen (thermal NO formation) and the oxidation of the fuel bounded nitrogen (fuel-NO).

Detailed kinetic models for predicting fuel NO with 29 elementary reactions are used, for example, by Ro and Lendt [11-12]. In the case of three - dimensional simulation, such models consume too much CPU - time. Therefore, global mechanisms are used. In FLOREAN for simulation of nitrogen oxides formation the Zel'dovich mechanism for thermal NOx [13], De Soete [14] or the Mitchell-Tarbell [15] mechanisms for fuel $\mathrm{NO}_{\mathrm{x}}$ formation are applied.

Depending on the coal type, fuel-bound nitrogen is released during pyrolysis and char burnout. It is supposed that the main gas species containing nitrogen produced during coal combustion are $\mathrm{HCN}$ and $\mathrm{NH}_{3}$. In some modeling approach, volatile and char, nitrogen is released only as $\mathrm{HCN}$ proportional to the char burnout rate. In FLOREAN, both $\mathrm{HCN}$ and $\mathrm{NH}_{3}$ release is possible.

De Soete mechanism. Recognizing the importance of $\mathrm{HCN}$ as a precursor to the subsequent nitrogen compound intermediates, De Soete [14] correlated the rate of $\mathrm{NO}$ formation and decay with a pair of competitive parallel reactions, each first order in $\mathrm{HCN}$ and $\mathrm{NH}_{3}$. This model describes the gas phase reaction of $\mathrm{HCN}$ and $\mathrm{NH}_{3}$ with an oxidation rate to $\mathrm{NO}$ and a reduction rate to $\mathrm{N}_{2}$. $\mathrm{HCN}$ and $\mathrm{NH}_{3}$ are competitevely oxidized and reduced according to the following generic scheme involving four reactions: 


$$
\begin{aligned}
& R_{1}=1.0 \cdot 10^{10} \cdot X_{H C N} \cdot X_{O_{9}}^{a} \cdot \exp \left(\frac{-33732.5}{T}\right) \\
& R_{2}=4.0 \cdot 10^{6} \cdot X_{N H_{3}} \cdot X_{O_{2}}^{a} \cdot \exp \left(\frac{-16111.0}{T}\right) \\
& R_{3}=-3.0 \cdot 10^{12} \cdot X_{H C N} \cdot X_{N O} \cdot \exp \left(\frac{-30208.2}{T}\right) \\
& R_{4}=-1.8 \cdot 10^{8} \cdot X_{N H_{3}} \cdot X_{N O} \cdot \exp \left(\frac{-13593.7}{T}\right)
\end{aligned}
$$

Mitchell and Tarbell model. A global model has been proposed by Mitchell and Tarbell [15], involving $\mathrm{NH}_{3}, \mathrm{HCN}, \mathrm{NO}$ and $\mathrm{N}_{2}$ as $\mathrm{N}-$ containing species. The first reaction step is the conversion of $\mathrm{HCN}$ to $\mathrm{NH}_{3}$ by an attack of an oxidizing agent.

The $\mathrm{NH}_{3}$ forms and destructs $\mathrm{NO}$ within a pair of competitive parallel reactions. In their global model, Mitchell and Tarbell propose the recycling of NO back to $\mathrm{HCN}$ through hydrocarbons $\mathrm{CxHy}$.

The postulated reaction rate of the NO recycling is not temperature dependent. The suggested value of the $\mathrm{C}$ atom number $\mathrm{x}$ in the hydrocarbons is eight [15], the value of $y$ is calculated from coal analysis. The $\mathrm{H}_{2}-$ concentration is calculated from equilibrium. In addition NO is reduced by a heterogeneous reaction between $\mathrm{NO}$ and char particles.

\section{Results of CFD Studies}

Kazakhstan has huge stocks of power resources, sufficient for covering own needs and export to other regions, both in a natural, and in the form of electric power. About $3.3 \%$ of world industrial stocks of coals are concentrated in Kazakhstan. More than $70 \%$ of the electric powers in Kazakhstan are generated in Thermal Power Plants.

FLOREAN has been applied for the calculation of a furnace chamber of Aksu power station fired with low grade coal of Ekibastuz (Kazakhstan). It has to be emphasized that in Kazakhstan thermal power plants predominantly use bituminous and sub- bituminous coals from Ekibastuz, Karaganda, Kuuchekinsk.

Coals from these basins have almost the same characteristics. All Kazakhstan coals are considered low rank. The moisture content varies from 5 to $40 \%$ and the high ash content is up to $55 \%$. The volatile matter content reaches up to $28 \%$. High ash content results in high fly ash contents in flue gases, which reach up to $60-70 \mathrm{~g} / \mathrm{m} 3$ for high ash coals.

Figure 1-3 show a firing system with 12-swirl burners, which are all in operation. The nozzles are located opposite to each other in two layers, 6 nozzles in each. In order to intensify the ignition process the air is fed to the chamber in such a way that oxygen, it contains comes into reaction gradually.

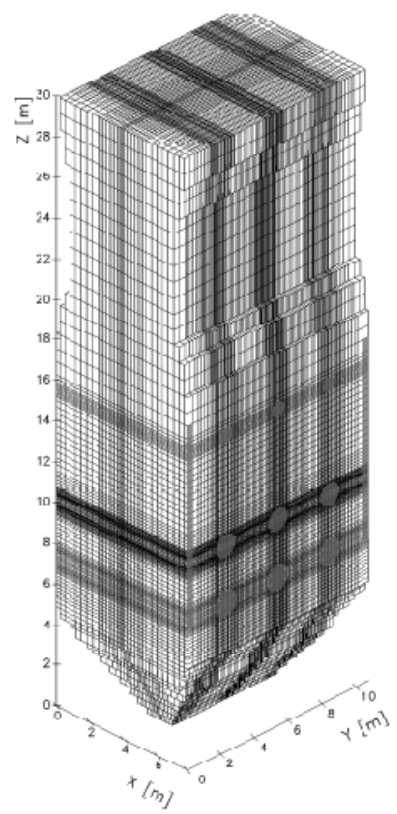

Figure 1 - Finite volume discretization grid of the furnace of the PK39 steam generator.
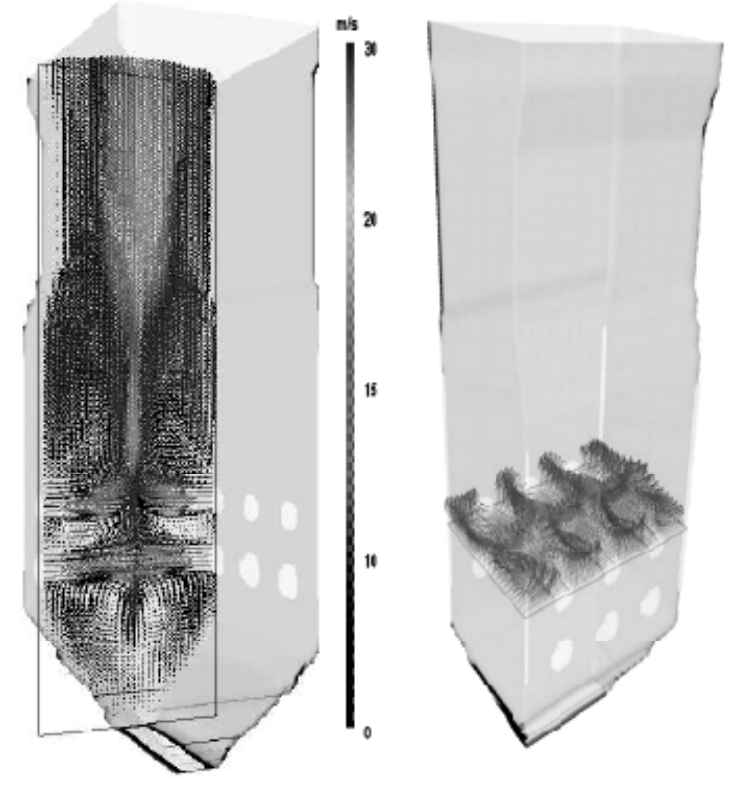

Figure 2 -Velocity distribution in the vertical mean cross section during coal combustion at $100 \%$ load.

The fuel in the layers is distributed equally, that caused the symmetrical flow fields (Fig.2 and Fig.3). Recirculating regions are formed close to the walls and four strong recirculating regions are formed in the corner regions at the burner levels (Fig.2). 


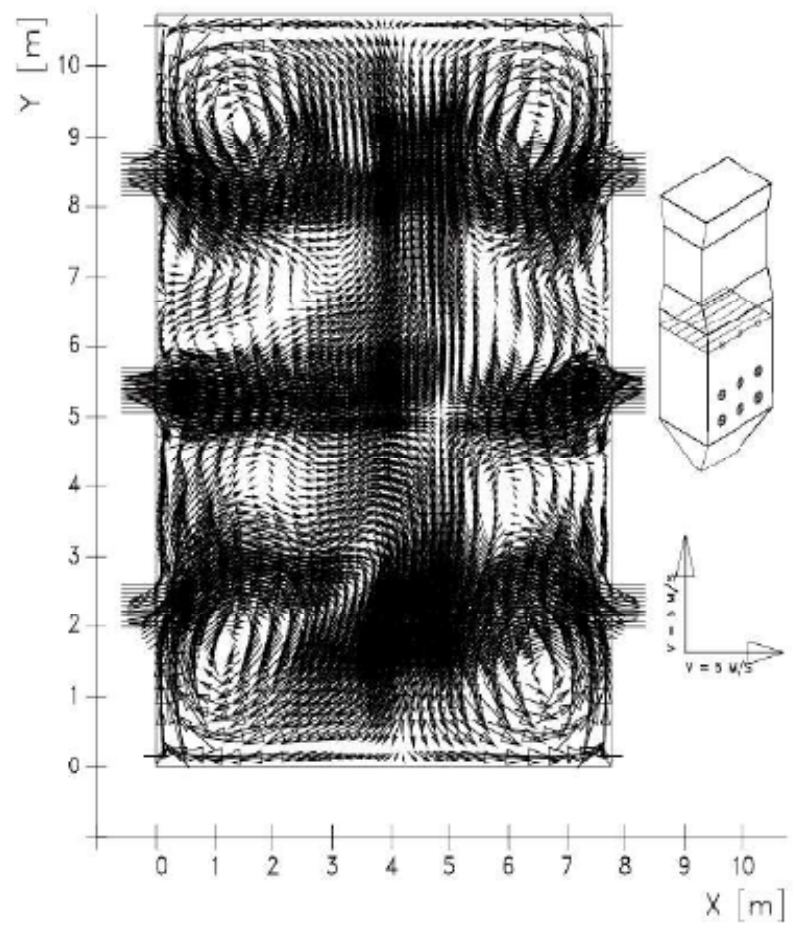

Figure 3 - Velocity distribution in the level of the OFA jets during coal combustion at $100 \%$ load.

Temperature distributions in the furnace for full load operation (with coal and oil combustion) are presented in the Fig. 4-9.

Temperature distributions in furnace volume for full load boiler operation with coal combustion are given on Figure 4 in the shape of temperature is surfaces. It has seen that zone of maximum tem-

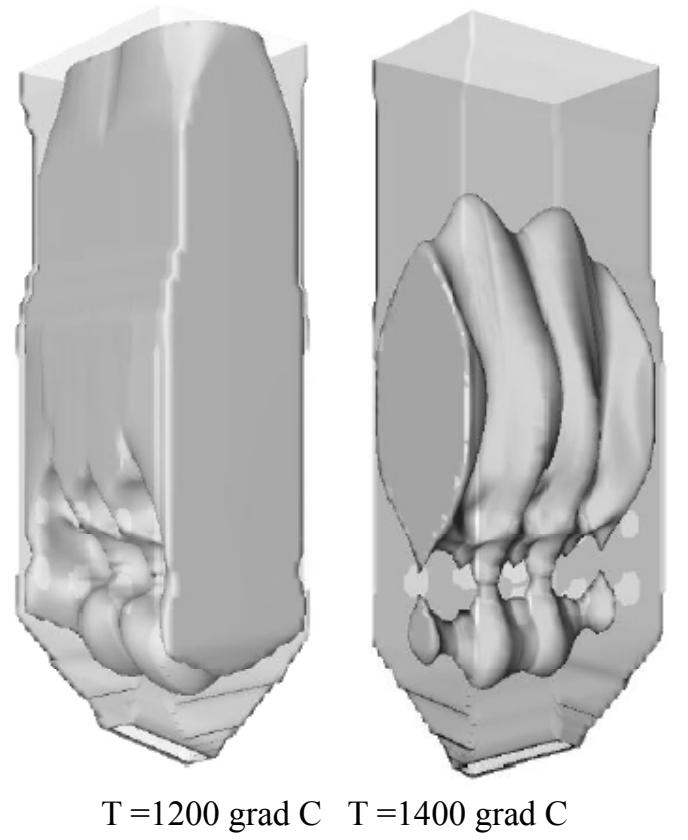

peratures are concentrated in the center of the firechamber on the level of the burners.

Fig. 5 and Fig. 6 show the temperature distribution different cross sections of the furnace: in the lower level of the burners and in vertical sections due to symmetry plane of combustion chamber.

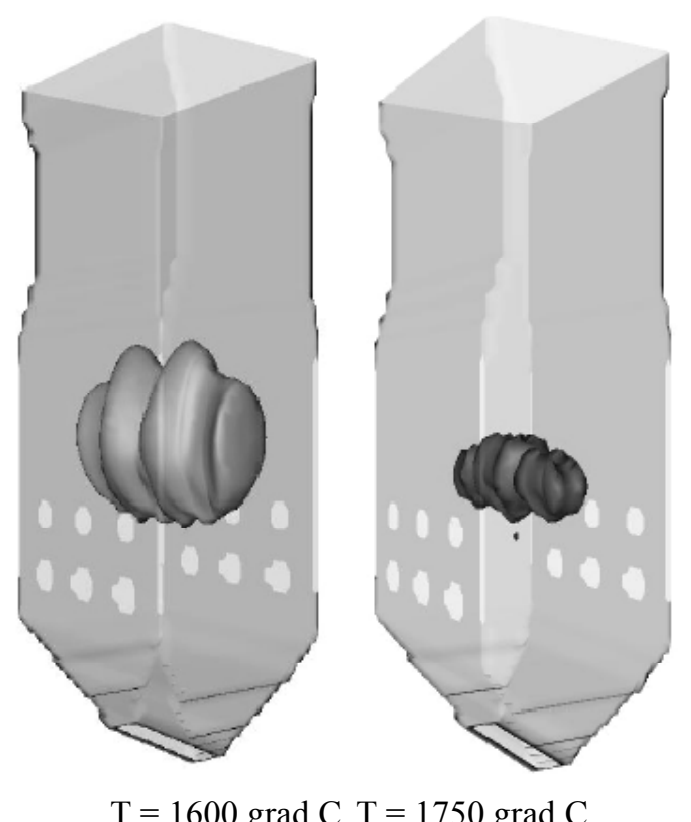

$\mathrm{T}=1600 \operatorname{grad} \mathrm{C} \mathrm{T}=1750 \operatorname{grad} \mathrm{C}$

Figure 4 - Temperature isosurfaces. 


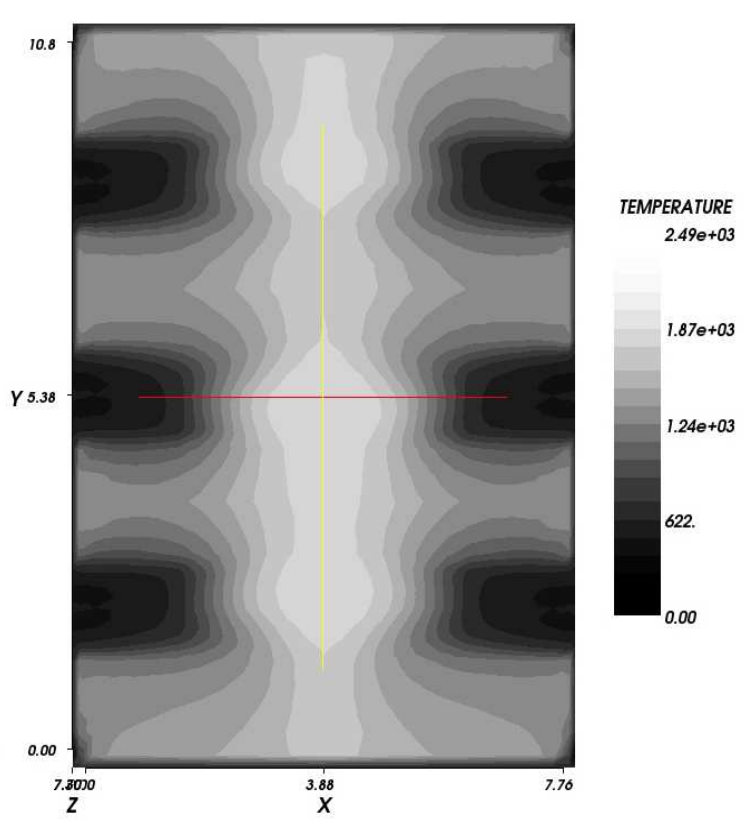

Figure 5 - Temperature distribution in cross-section of the furnace in the lower level of the burners.

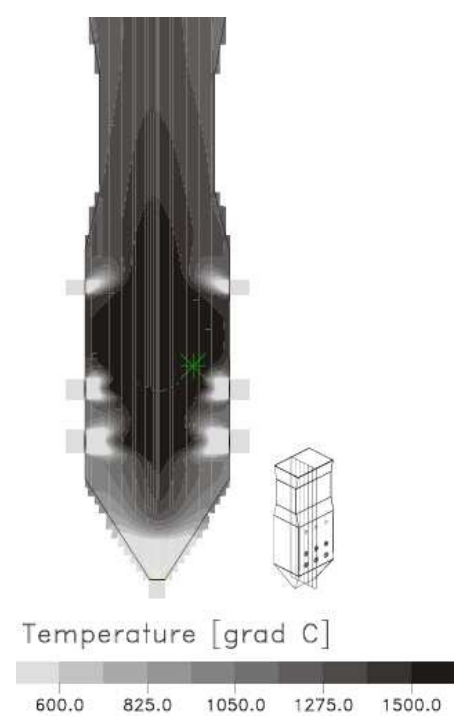

Figure 7 - Temperature distribution in the middle vertical section during coal combustion at $100 \%$ load.

To reduce NO emissions air staging was used. The penetration of the over fire air jets into the furnace can be seen in the velocity (Fig.3) and temperature (Fig.8) distribution. A significant increase of the flue gas temperature arises along the jets induced by the carbon monoxide combustion.

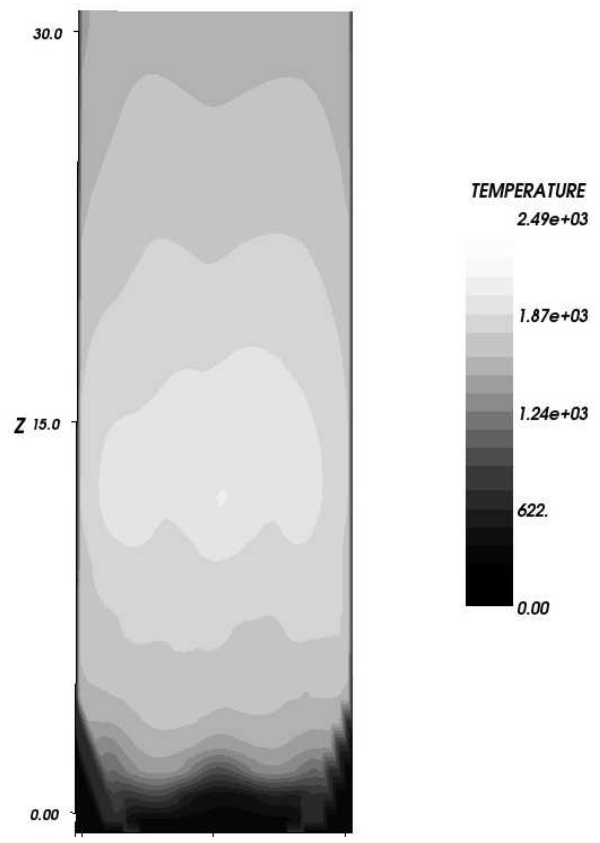

Figure 6 - Temperature distribution in cross-section of the furnace in the lower level of the burners.

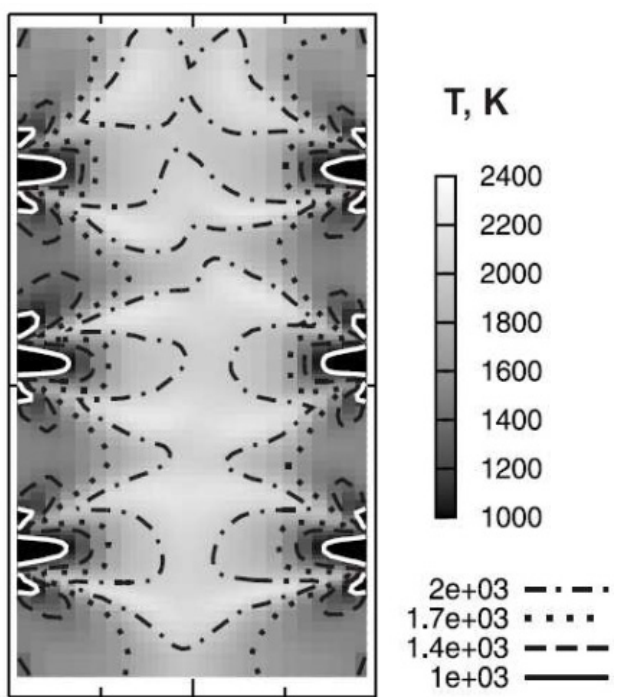

Figure 8 - Temperature distribution at the burner level for oil combustion at $100 \%$ load.

Temperature distributions in the furnace for full load operation with oil combustion are given at Figure 9.

Fig. 9-17 shows results of combustion products calculations for low-grade Kazakhstan hard coal power station. Concentration is osur faces show concentration of $\mathrm{O} 2$ (Fig.10), CO (Fig.12) and 
$\mathrm{CO} 2$ (Fig.15) distribution inside of the furnace space and over furnace height.

The picture of fuel burning out is shown in Figure bellow by fields of concentration of oxygen
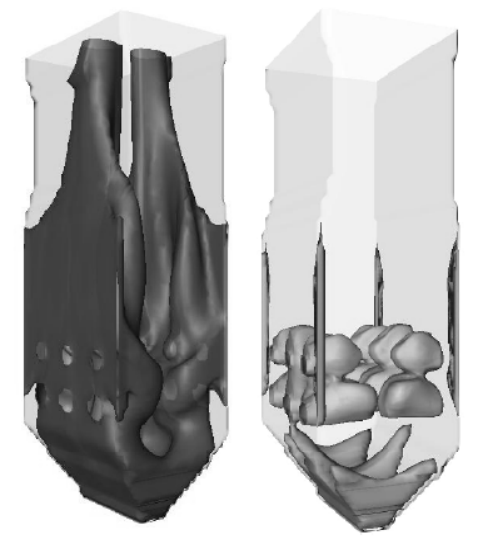

$\mathrm{CO}_{2}=0.05 \mathrm{~kg} / \mathrm{kg} \quad \mathrm{CO}_{2}=0.10 \mathrm{~kg} / \mathrm{kg}$

Figure 9 - Oxygen isosurfaces.

In the model for combustion products, formation three different reactions between char and flue gas are considered. The oxidation of the char to carbon monoxide or carbon dioxide and the reduction of carbon dioxide at the surface of the char particle to carbon monoxide.

The model incorporates the different effects of
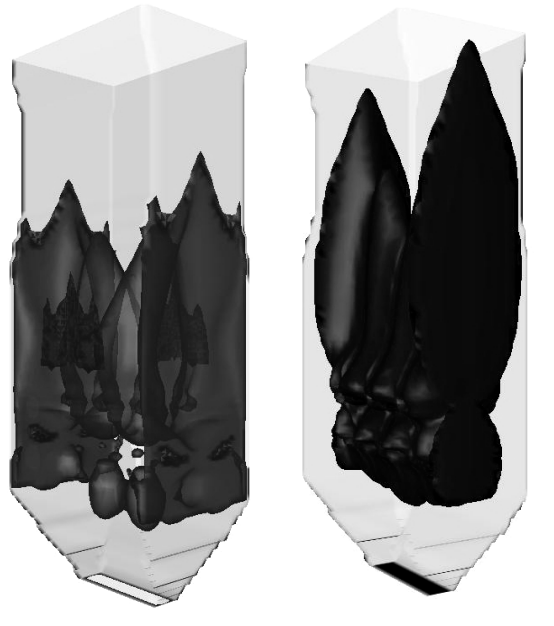

$\mathrm{CO}=5.103 \mathrm{mg} / \mathrm{Nm} 3$

$$
\mathrm{CO}=2.103 \mathrm{mg} / \mathrm{Nm}^{3}
$$

Figure 11 - Carbon monoxide isosurfaces.
O2 (Fig.11), carbon monoxide CO (Fig.13) and carbon dioxide $\mathrm{CO} 2$ (Fig.16) over furnace height during coal combustion at $100 \%$ load.

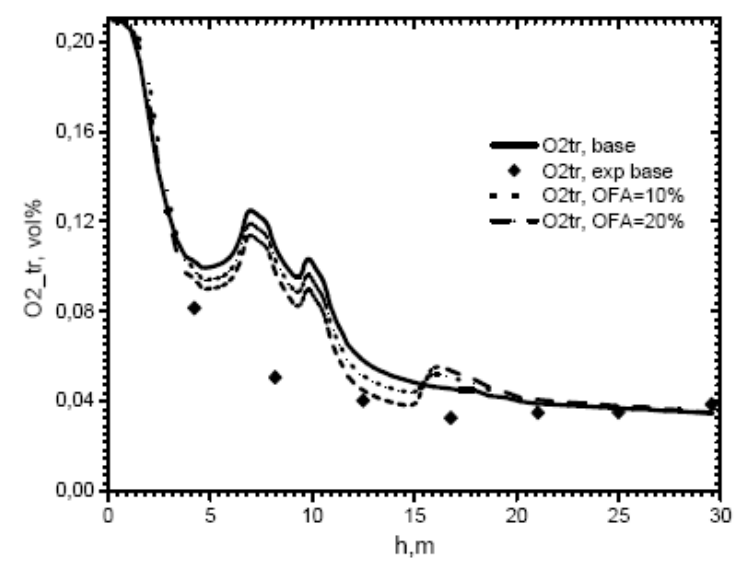

Figure 10 - Simulated oxygen distribution over furnace height during coal combustion at $100 \%$ load compared with experiment [17].

oxygen and carbon dioxide diffusion to the particle surface and in the pores and the kinetics of the chemical reaction at the surface as a function of temperature and particle diameter.

Due to the CO reactions also at lower temperatures, $\mathrm{CO}$ concentration is further reduced in the gas path after the furnace outlet.

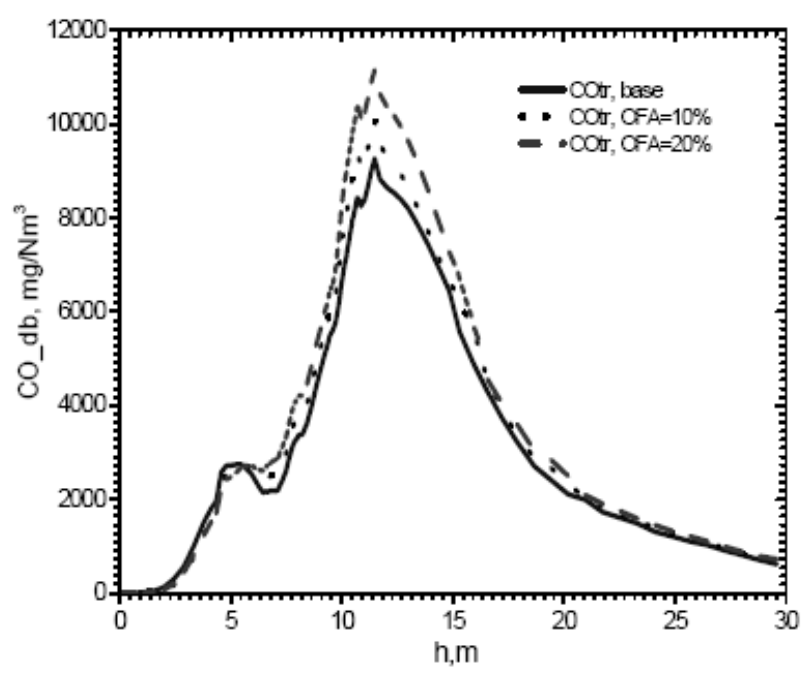

Figure 12 - Simulated carbon monoxide distribution over furnace height during coal combustion at $100 \%$ load. 


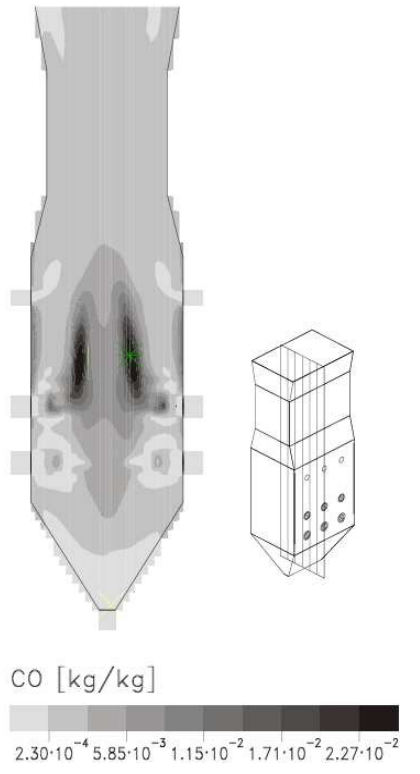

Figure 13 - $\mathrm{CO}$ concentration in the middle vertical section during coal combustion at $100 \%$ load.

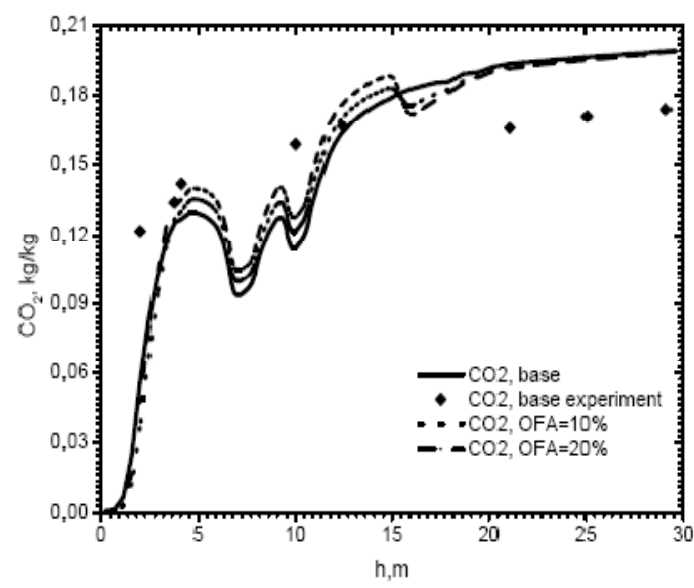

Figure 15 - Simulated carbon dioxide distribution over furnace height during coal combustion at $100 \%$ load compared with experiment [17].
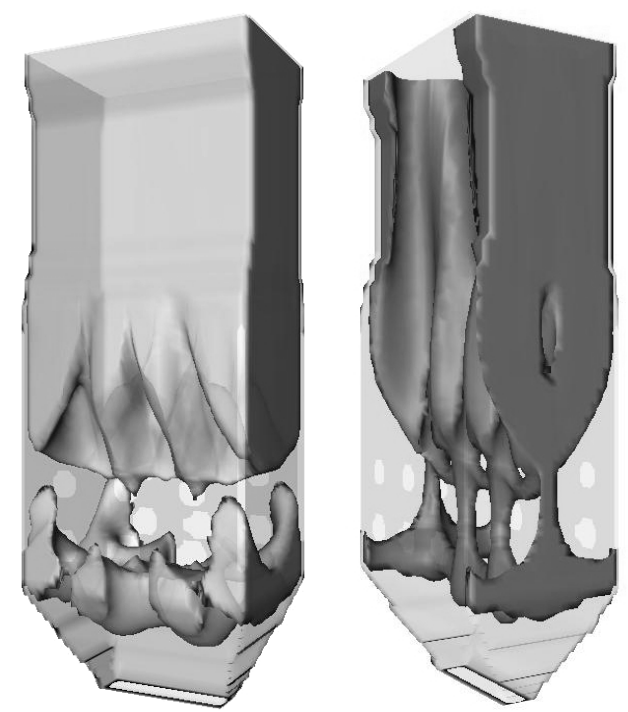

$\mathrm{CO}_{2}=0.12 \mathrm{~kg} / \mathrm{kg}$

$\mathrm{CO}_{2}=0.16 \mathrm{~kg} / \mathrm{kg}$

Figure 14 - Carbon dioxide issurfaces.

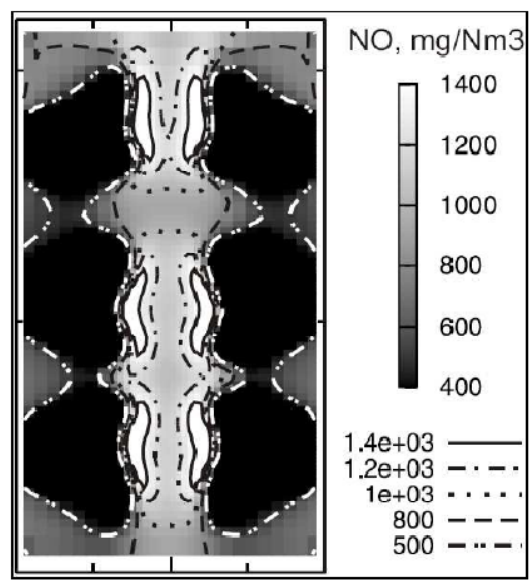

Figure 16 - NO-concentration at the burner level during coal combustion at $100 \%$ load.

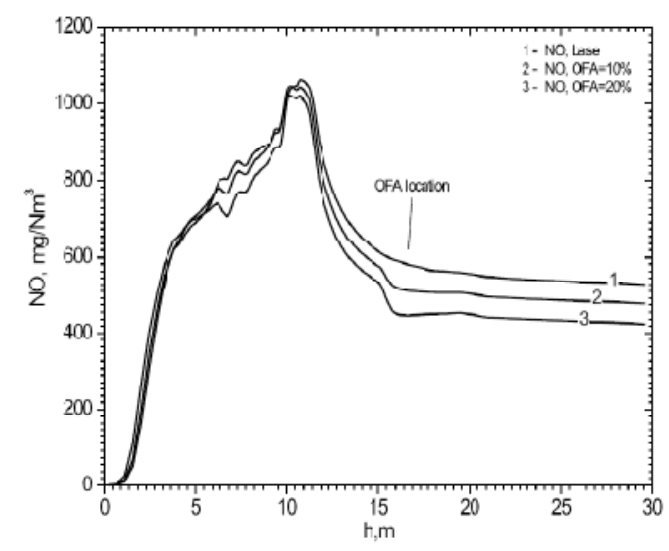

Figure 17 - NO-concentration distribution over furnace height during coal combustion at $100 \%$ load.

International Journal of mathematics and physics 5, №1, 60 (2014) 
The $\mathrm{NO}_{\mathrm{x}}$ model is realized separately as post processing. It is made under the assumption that the pollutant formation has no influence on the fluidflow, temperature distribution etc. This assumption is reasonable due to the small concentrations of the pollutants.

The NOx formation in the furnace has been in vestigatedby applying ama the matical model with two kinetics. This model alsohelps to study the in fluence of various parameter son the net production of NO (for example in fluence of OFA etc).

\section{Conclusion}

By means of the 3D CFD tool FLOREAN numerical simulations have been carried out to predict gas flow, species concentrations, temperature fields due to combustion, radiation and convective heat transfer and the pollutant formation and destruction in furnace chambers of Kazakhstan Power Plants.

The purpose of the presented research was to investigate numerically the characteristics of reacting flows and heat transfer due to oil and coal turbulent combustion in large-scale boiler furnaces. The data resulting from the present study allow an improved understanding of combustion processes and provide detailed description of furnace performance.

Results from CFD simulation can be useful for engineers to choose an appropriate burner and furnace design, to reduce pollutant emissions, as well as to optimize furnace operation.

\section{References}

1. Leithner R., Müller H. CFD studies for boilers //Second M.I.T. Conference on computational Fluid and Solid Mechanics. - M.I.T., Cambridge.2003 P.15-35.

2. Epple B., Leithner R., Linzer W., Walter H. Simulation von Kraftwerken und Wärmetechnischen Anlagen. ISBN: 978-3-211-29695-0.XLIV.- 2009. P.17-22.

3. Zindler H., Walter H., Hauschke A., Leithner R. Dynamic Simulation of a 800 MW Hard coal one-through supercritical power plant to fulfill the Great Britain grid code // Proceedings of $6^{\text {th }}$ IASME/WSEAS Int. Conference on Heat transfer, thermal engineering and environment.- Rhodes.Greece.- 2008.-P.184 -192.

4. Müller H. Numerische Berechnung Dreidimensionaler Turbulenter Strömungen in Dampfer- zeugernmit Wärmeübergang und Chemischen Reaktionen am Beispiel des SNCR- Verfahrens und der Kohleverbrennung. Fortschr.- Ber. VDIVerlag. Vol. 6, 1992, 158 p.

5. Lockwood F. etc. An improved flux model for thecalculation of radiation heat transfer in combustion chambers //ASME Paper 76-HT-55.- 1976.

6. Lockwood F., Shah N.G. A new radiation solution method for incorporation in general combustion procedures //18.Symp. (International) on Combustion.- The Combustion Institute.-1981.P.1405-1414.

7. Domke K., Computer graphics and radiative heat exchange - similarities and differences in description and calculation methods // A Series of Reference Booksand Textbooks, $6^{\text {th }}$ IASME / WSEAS Int. Conference on Heat transfer, thermal engineering and environment. - Rhodes.- Greece.August 20 - 22.- 2008.-P.271-276.

8. Brandt F., Brennstoffe und Verbrennungsrechnung FDBR, Fachbuchreihe Bd. 1 Vulkan Verlag Essen.- 1981.

9. Magnussen B. F., etc. On the mathematical modeling of turbulent combustion with special emphasis on soot formation and combustion //16th Symp. (Int.) Combustion.-1976.-P.719-729.

10. Hansen W. Ölfeuerungen. Brennstoff, Technische Einrichtungen, Anwendungen. Springer Verlag, 1970, $455 \mathrm{p}$.

11. Lendt B. Numerische Berechnungder Stickoxid-konzentration in Kohlenstaubflammen Ein Vergleichunters chiedlicher Reaktionsmodelle. VDI-Verlag. - 1991. - Reihe6.- №254.-P.195.

12. Ro S. Numerische Berechnung der NOxBildung in Kohlenstaubflammen - Einfluss desDralles und Brennstoffstickstoffgehaltes.VDIVerlag.-Reihe 6.- №271.- 1992.-P.184.

13. Zeldovich Y.B. The oxidation of nitrogen in combustion explosions. ActaPhysicochim.USSR.-21.-1946.- P.577-628.

14. De Soete G. Overall reaction rates of NO and $\mathrm{N}_{2}$ formation from fuel nitrogen $/ / 15^{\text {th }}$ international symposium on combustion. - Pittsburgh.USA.- The Combustion Institute.- 1975.-P.10931102 .

15. Mitchell J., Tarbell J. A kinetic model of nitric oxide formation during pulverizedcoal combustion, AIChE Journal. - 1982. -P.302-320.

16. Aliarov B.K., Ustimenko B.P., Buhman M.A. Development and inculcation vertical threechannels burners on the boilers PK-39 Ermnakovskaja Power Plant. Report №01910010550.-Kaz. SRIETP.-Almaty.- 1991.- 59 p. 